\title{
Sero-epidemiology of Hepatitis C Virus and Malaria (Plasmodium falciparum) Co-infection among pregnant women Attending National Hospital Abuja in Central Nigeria
}

ASAGA MAC PETER ( $\sim$ pasaga123x@gmail.com )

UNIVERSITY MEDICAL CENTRE, FREIBURG https://orcid.org/0000-0003-0038-8896

HALIMA SALIHU

Nasarawa State University

AMALI OKWOLI

Federal University of Agriculture Makurdi

Research article

Keywords: Hepatitis C Virus, Malaria, Plasmodium falciparum, Sero-prevalence, pregnant women

Posted Date: April 30th, 2019

DOI: https://doi.org/10.21203/rs.2.9412/v1

License: (c) (1) This work is licensed under a Creative Commons Attribution 4.0 International License.

Read Full License 


\section{Abstract}

Background Hepatitis $\mathrm{C}$ virus is an RNA virus of the flaviviridae family and appears to have humans and chimpanzees as the only species susceptible to its infection [1]. Infection is often asymptomatic but once established, chronic infection can lead to scarring of the liver (fibrosis) and advanced scarring (cirrhosis) which is generally apparent after many years [2]. It is a major and growing public health problem that can easily lead to chronic liver disease, cirrhosis and hepatocellular carcinoma [3]. Methods This study was conducted on one hundred and thirty (130) pregnant women of reproductive age ( $15-45$ years) who were randomly selected at National hospital Abuja. $5 \mathrm{ml}$ of blood was obtained from study participants for rapid HCV screening and malaria thick films and thin films for parasite densities and parasite species identification. Result The preponderance of HCV was 130 (17.1\%), malaria (49.4\%) and HCV and malaria co-infection was (10.9\%), of the hundred and thirty (130) samples obtained from pregnant women in the Abuja National Hospital. Conclusion The sero-prevalence of HCV infection and its infectivity is high in central Nigeria. This study findings guide the want for routine HCV and malaria screening among pregnant women at some stage in antenatal care within the region and Nigeria. It also form a base for continual education campaign about HCV amongst rural/Urban pregnant mothers/women and food vendors in central states and other parts of Nigeria. Those efforts will guarantee top of the line and better outcome for excellent health care delivery for the expecting mothers and other health care providers in our hospitals.

\section{Background}

Hepatitis C virus (HCV) is an RNA virus of the flaviviridae family and appears to have humans and chimpanzees as the only species susceptible to its infection [1]. Infection is often asymptomatic but once established, chronic infection can lead to scarring of the liver (fibrosis) and advanced scarring (cirrhosis) which is generally apparent after many years [2]. It is a major and growing public health problem that can easily lead to chronic liver disease, cirrhosis and hepatocellular carcinoma [3].

The importance of understanding hepatitis $C$ during pregnancy is linked to adverse maternal and neonatal results. There is a potential for chronic hepatitis $\mathrm{C}$, cirrhosis or hepatocellular carcinoma in infants infected through vertical transmission [4]. When mothers are co - infected with malaria or human immunodeficiency virus (HIV) or have a high viral load, the risk of vertical transmission is increased. There are no clear data to support the increased or reduced risk of the infection during delivery [4].

\section{Methods}

\section{Study Area}

This study was conducted in the Abuja Federal Capital Territory National Hospital, Abuja. Abuja has a population of over 3 million people. It's the Federal Republic of Nigeria's seat of government.

\section{Study Population}


This study was conducted on one hundred and thirty (130) pregnant women of reproductive age (15 - 45 years) who were randomly selected at National hospital Abuja. A Structured questionnaires requesting certain demographic information (Additional files for a sample of the questionnaire) were given to each pregnant woman and all obtained data were treated confidentially. Inform consent of patients were obtained preceding the start of the study.

\section{Sample Collection}

Five millilitres $(5 \mathrm{ml})$ of whole blood were collected by venepuncture from each subject's cubital vein into specimen bottles (anticoagulant bottles containing K2EDTA for malaria parasite testing and plain bottles for hepatitis $\mathrm{C}$ surface antigen screening).

\section{HCV serology}

The clotted blood was centrifuged to separate the serum from whole blood, for rapid Anti-HCV test, one step HCV (Serum/plasma) 3.5mm SD BIOLINE was used. It is a rapid immune chromatographic direct binding test for the visual detection of hepatitis $C$ virus antibodies in serum/plasma samples in the diagnosis of hepatitis $\mathrm{C}$ infection, and was used according to manufacturer protocol and SOP. The test sensitivity and specificity of SD BIOLINE for rapid Anti-HCV test is $97.25 \%$ and $99.43 \%$, respectively.

\section{Malaria Parasite Detection (Microscopy)}

A total of one hundred and thirty pregnant women (130) participants were screened for Plasmodium falciparum infection [5]. Procedure for parasitic staining were adopted using Giemsa staining at pH 7.2.

\section{Procedure}

A small drop of blood was placed in the centre of a labelled frosted slide pre-cleaned with $70 \%$ alcohol and dried. Using the corner of another slide, the drop was spread in a circular pattern to a diameter of 15 $\mathrm{mm}$ and smears allowed to dry. The slides were stained with $10 \%$ Giemsa solution $(\mathrm{pH} \mathrm{7.2)}$ for 8-10 minutes. Stained slides were examined under the light microscope using $\times 100$ objective lens (immersion oil). The thick films were to identify the parasite densities while thin films were used to identify the parasite species.

\section{Statistical Analysis}

The data was analyzed using SPSS 20.0 statistical software using descriptive statistics tables and graphs, chi square test was employed to determine the relationships between prevalence, demographics and risk factors. $P$ value less than 0.05 was considered significant.

\section{Inclusion Criteria}

Patient not treated previously or just beginning treatment for HCV 
Patient that signed the informed consent to participate in the study

Group A- Patient with HCV mono-infection

Group B- Patient with HCV and malaria co-infection

\section{Exclusion Criteria}

Patient that received previous treatment of HCV

Patient currently on malaria drug.

Subjects who refuse to take part in the study.

\section{Results}

\section{Seroprevalence of Hepatitis C Virus Infection among pregnant women attending National hospital Abuja.}

The preponderance of HCV was 130 (17.1\%), malaria (49.4\%) and HCV and malaria co-infection was $(10.9 \%)$, of the hundred and thirty (130) samples obtained from pregnant women in the Abuja National Hospital.

The prevalence of HCV in pregnant women was 9 (19.2\%) in the 15-25-year age group, 10 (17.2\%) in the 26-36-year age group and > 37-year age group $3(12.0 \%)$. The prevalence of HCV in blood transfusion was $2(7.7 \%)$ and non-transfused subjects $20(19.2 \%)$. Individuals with a history of previous surgery had a prevalence of $8(25.8 \%)$ and no history of surgery, 14 (14.1\%). HIV-positive people who were coinfected with HCV had a prevalence 7 (30.4\%) and 15 (14.0\%) for HIV-negative subjects [Table 1]. There was no significant difference between $\mathrm{HCV}$, social demographics and other diverse factors.

The predominance of HCV in marital status was $(6.3 \%)$ in single persons, $(19.8 \%)$ in married persons and divorced persons $(0 \%)$. The prevalence of family types was $(11.8 \%)$ in monogamous and $(24.1 \%)$ in polygamous families. The prevalence of HCV among subjects with body piercing types was (40.0\%) in tattoos, $(17.0 \%)$ in tribal marks and (15.3\%) in non-scarified individuals [Table 2]. The prevalence of HCV among the various educational strata was (20\%) prevalence for Islamic qur'anic pupils, $(9.1 \%)$ among primary school pupils, $(15.9 \%)$ in high school students and (18.6\%) tertiary/University students. The prevalence of pregnant women with no formal education was (18.2\%). There was no statistical significant difference between HCV and the social factors [Table 2].

The prevalence of malaria in relation to age was (57.5\%) in the age group $15-25,(65.5 \%)$ in participants aged 26-36 and (52.0\%) in the age group > 37. Individuals who had blood transfusion had a prevalence of malaria (61.5\%) and (59.6\%) among non-transfused participants. Individuals with previous history of surgery had a prevalence of malaria (93.6\%), while those without previous surgery had a prevalence of malaria (49.5\%). HIV-positive and negative people showed a prevalence of malaria $(11.2 \%)$ and $(28.0 \%)$. There was no significant difference between the above mentioned factors and malaria. [Table 3]. 
The predominance of malaria among the different marital status was (6.3\%) for single persons, $(19.8 \%)$ for married persons and divorced persons $(0 \%)$. The prevalence of Plasmodium faciparum for family types was $(11.8 \%)$ for monogamous and $(24.1 \%)$ in polygamous. Types of body piercing showed a prevalence of $(60 \%)$ among tattoo bearers, tribal marks (56.6\%) and non-tribal marks $(62.5 \%)$. Islamic qur'anic pupils convey a (60\%) prevalence, a pervasiveness of $(72.7 \%)$ malaria infection was observed in primary school pupils, (56.6\%) in high school students (50.5\%) and (63.6\%) amid tertiary schools and non-formal education sectors. [Table 4]. There was no significant difference between malaria and this socio-demographic groups.

The prevalence of HCV and malaria co-infection in dispersion through the different age groups were (14.9\%) among $15-25$ years old, (10.4\%) for 26-36 years of age and those $>37$ years old showed a prevalence of (4.5\%). Participants who had a blood transfusion and those who did not, showed a prevalence of $(7.7 \%)$ and $(11.5 \%)$ respectively, the prevalence for those who had a history of surgery and those without a history of surgery was $(22.6 \%)$ and $(7.1 \%)$ distributively. The prevalence of HIV-positive people co-infected with HCV and malaria was (8.7\%) and (11.2\%). There was no significant statistical difference between this demographic factors and HCV and malaria co-infection [Table 5].

\section{Discussion}

In this study, a ponderous sero-prevalence of HCV and malaria co-infection of 130 (10.9\%) was observed in pregnant women attending pre-natal care in National hospital, Abuja Nigeria, this is the first study to address HCV and malaria co-infection in Nigeria. Additionally the transmission of HCV from mother to child is assessed at $4-8 \%$, but there is transmission rate increments of $17-25 \%$ if the mother is additionally co-infected with malaria. The worldwide prevalence of HCV infection in pregnant women is evaluated to be 1 and $8 \%$, and in children between $0.05 \%$ and $5 \%$ [6]. The anticipation of vertical transmission is exceptionally vital, since the disease at infancy or earliest stages more often than not leads to an incessant (chronic) carrier status [7].

\section{Immunology of HCV and Malaria Co-infection}

Immunological highlights of Malaria and HCV co-infection, hepatic organized infection appeared to trigger an early $T$ cell-independent cytokine response along with a delayed cytokine response that is concurrent with the infiltration of $T$ cells. On the other hand, the $T$ cell responses always appeared early in the blood stages compared to hepatic stage infection, possibly because parasitemia is detectable and a T cell-independent phase is not seen, this basically reflecting that it is actuated by infected hepatocytes. However, in both cases the cytokine responses generated are accompanied by a decrease in HCV RNA and DNA in the liver [8]. Infections of HCV and malaria use common host factors such as HSPGs, CD-81, SR-B1 and ApoE [7].

\section{Seroprevalence of HCV and Malaria}


A review carried by Gasim et al [9] showed a prevalence of HCV to be 7.3\% among Sudanese women. Pennap et al, 2010 reported that HCV is more predominant in female compared to HBV, but there was no clear reason to underpin her findings. In contrast to a comparable investigations conducted in Jos, Nigeria on HCV, where a pervasiveness of (12.3\%) and (13.6\%) were exuded. In this study $(17.1 \%)$ prevalence of HCV was observed among the participants. This may well be credited to study area, health facilities, strategies utilized as well as test estimates and other sociodemographic characteristic and well of life of subjects under investigation in the two studies.

Malaria co-infection prevalence was also investigated among the subjects assessing medical care at National hospital Abuja, a prevalence of (49.4\%) was reported, this is in variance with the study of Okwa [10], Aribodor et al [11] which conveyed a preponderance of (63.6\%). This could be as a result of health facilities, education, and the use of long last insecticide treated nets by antenatal women in Abuja compared to the other former. Also, intermittent preventive treatment with pyrimethamine sulfadoxine $(\mathrm{sp})$ is a common practice observed at Abuja national hospital health facilities. Pregnant women are more likely to have perceptible malaria than are their non-pregnant peers, and the overabundance chance of the disease varies with gravidity. Pregnant women going to antenatal clinic for their first visit are a potential pragmatic sentinel group to track the intensity of malaria transmission and HCV; however, the relationship between the predominance of malaria in neonates, a standard measure for estimating endemic malaria and pregnant women has never been compared anywhere[12].

The prevalence of HCV and malaria co-infection was highest (14.9\%) [Table 5] among age group 15-25 years compared to the other age grade $(10.4 \%$ and $4.4 \%)$. This is a total deviation from a similar study conducted by[13] in Egypt where the prevalence were $0.2 \%$ to $5 \%$. The discordance in result may be attributed to self-limiting of HCV as a child grows older and subsequently becomes or attained the chronic carrier status. This constitute a serious public health concern among the Nigeria populace as this group act as plausible transmission point among various communities both at rural and urban settings. Participants with history of a blood transfusion and those with no transfusion narrative or antiquity showed a prevalence of $(7.7 \%)$ and $(11.5 \%)$ respectively. This could be attributed to screening of blood products by the healthcare provider(s) before transfusion compared those who have never received blood before, among these maybe possibly chronic carriers of the virus which is why a higher pervasiveness. Meanwhile, those who had a history of surgery revealed a prevalence of $(22.6 \%)$ and those with no history of surgery (7.1\%). HIV positive individuals co-infected with HCV and malaria showed a prevalence of $(8.7 \%)$ and $(11.2 \%)$ respectively. Sociodemographic indices showed a myriads of prevalence variations among the different groups; polygamous individuals had the most elevated $(24.1 \%)$ prevalence compared to monogamous $(11.8 \%)$, married women( $19.8 \%)$, singles $(6.3 \%)$ and divorced had no positive $(0 \%)$ individuals \{Table 3]. The main deductive reasoning attribute to this in the present study could be life style, social activities and awareness. Body piercing of various types in the current study showed an overall prevalence of (24\%). Scarification has been shown to transmit HCV; this could result from the use of contaminated instrument during the art of piercing. $[14,15,16]$ reported similar findings. 
Woman who attended Islamic qur'anic school showed a highest prevalence of (20\%).Tertiary education level showed a prevalence of (18.6\%) compared to the other levels of education [Table 2], no formal education (18.2\%), women who had attained secondary and primary school level had a prevalence of (15.9\%) and (9.1\%) respectively. The highest prevalence of HCV and malaria co-infections were recorded among women who had quranic form of education, it could be attributed to have arisen from polygamous form of marriages. It is a religious injunction or obligation among Muslim cleric that a man is obligated to marry four wives, as a result the manifestation(s) of high preponderance. It could also be asserted that their secluded (indoors all times) nature might have led to low level of awareness about $\mathrm{HCV}$, also 1nto 2 antenatal visit during pregnancy is a pointer. Oni et al [17] 2005 asserted that, the higher the level of education, the more likely the sexual adventure which often times involves multiple partners. The findings in this study exhibited a total contrast from the former. However, it is in consonance with the findings of [18] which reported that participants with HCV infection were less likely to be educated or married.

Malaria showed a high prevalence among all age groups, this could be as a result of holo-endemic nature of malaria in low middle income countries like Nigeria. The parasite density was gross among all age groups. Pregnant women generally are a risk group for malaria, a study in Asia Pacific region [19] reported that pregnant women are at greater risk of severe malaria in most endemic areas during their gravid period. In the current study pregnant women who had received blood during pregnancy had a prevalence of $(61.5 \%)$ compared to $(59.6 \%)$ those who never underwent a blood transfusion. This could be attributed to non-screening of malaria parasite during blood donation in most health facilities in Nigeria. Transfusion malaria still remains one of the most common transfusion-transmitted infections today $[20,18]$. The risk of acquiring transfusion malaria is very low (1 case per 4 million) in non-endemic countries such as the United States, whereas in the endemic countries like Nigeria, it is much higher ( $>50$ cases per million donor units) [21, 22],[Table 3].

Women with previous history of surgery had a prevalence of (93.6\%) malaria infection compared to those with no history of surgery (49.5\%). This could be ascribed to induced malaria during transfusion and most of the study subjects were living in communities or suburban know for poor hygiene and environmental practices. Similar finding were deduced form Uneke et al [23] [Table 3]. In various literatures on malaria, pregnant women co - infected with malaria and HIV are alleged to suffer from anaemia and poor birth results. In this study, the prevalence of HIV - positive pregnant women was (12\%) compared to negative pregnant women (28\%).

The prevalence of malaria among the different marital status was (62.5\%) among singles, $(29.4 \%)$ married women and (62.5\%) Divorced women, family types had a prevalence of $(59.2 \%)$ and $(61.1 \%)$ among monogamous and polygamous families respectively. Body piercing types showed a prevalence of $(60 \%)$ among tattoo bearers, $(56.6 \%)$ tribal and (62.5\%) non-tribal scarification. Islamic qur'anic pupil had $(60 \%)$ prevalence, $(72.7 \%)$ in primary school pupils, $(56.6 \%)$ in secondary school pupils, $(50.5 \%)$ and $(63.6 \%)$ in tertiary and non - formal education groups. However, women who do not attend antenatal clinic are at a greater risk of malaria given that antenatal clinic attendance can be low in some rural 
populations, and in women with low socioeconomic status; both of these factors have been associated with an increased risk of malaria $[9,16]$. A general lack of health information and awareness among poor and system marginalized groups can greatly reduce the demand for healthcare services. In addition, ethnic minorities might hold beliefs and perceptions about health and illness that influence health seeking. Knowledge of malaria might be lower among poor than non-poor households for several reasons. Information, education and communication (IEC) material for malaria might not reach poor people. Illiterate people and those with low levels of education might be unable to understand written health education materials, such as posters and flyers. Higher prevalence of malaria among singles and divorced women may be attributed to life style and social deviations. Similar findings were reported by Nwuzo et al [24]. The prevalence of monogamous family subjects were lower compared to polygamous pregnant women subjects. The main deductive attribute could be the influenced of many factors, such as difficulties in accessing quality healthcare and facilities. In addition, socio-cultural practices in rural areas may limit the resources available to pregnant women from polygamous homes compared to monogamous, resulting in adverse health consequences and outcomes. Studies in Gambia [25] and Tanzania Nita [26, 27], exudes similar findings.

\section{Discussion}

It is a known fact that both Plasmodium spp. and HCV infect liver cells; therefore, given the epidemic overlap of hepatitis $\mathrm{c}$ and malaria in certain areas of the world, it is plausible that they could infect and replicate in the same cell. It is also plausible that these two diseases could be co-infected, in that case, one pathogen can cause the other's severity to increase or decrease and vice versa. In addition, while HCV attachment and entry have been studied extensively due to its increasing worldwide prevalence, the entry of plasmodium into host hepatocytes is still to be examined.

Due to the increased resistance to anti-viral and anti-malarial treatments, it is essential to investigate and develop all possible routes of entry into the liver of both pathogens. It is also imperative to investigate the two pathogens co - infection, which will help develop new therapies and diagnostic tools. Pregnant subjects in this part of the world endure agony and distress from malaria, and when co-infected with HCV, it is better to imagine the two pathogens than they can actually be managed.

The seroprevalence of HCV and malaria infectivity is high in central Nigeria. This study findings guide the want for routine $\mathrm{HCV}$ and malaria screening among pregnant women at some stage in antenatal care within the region and Nigeria. It will also form a base for continual education campaign about HCV amongst rural/Urban pregnant mothers/women and food vendors in central states and other parts of Nigeria. Those efforts will guarantee top of the line and better outcome for excellent health care delivery for the expecting mothers and other health care providers in our hospitals.

\section{Conclusions}


It is a known fact that both Plasmodium spp. and HCV infect liver cells; therefore, given the epidemic overlap of hepatitis $\mathrm{c}$ and malaria in certain areas of the world, it is plausible that they could infect and replicate in the same cell. It is also plausible that these two diseases could be co-infected, in that case, one pathogen can cause the other's severity to increase or decrease and vice versa. In addition, while HCV attachment and entry have been studied extensively due to its increasing worldwide prevalence, the entry of plasmodium into host hepatocytes is still to be examined.

Due to the increased resistance to anti-viral and anti-malarial treatments, it is essential to investigate and develop all possible routes of entry into the liver of both pathogens. It is also imperative to investigate the two pathogens co - infection, which will help develop new therapies and diagnostic tools. Pregnant subjects in this part of the world endure agony and distress from malaria, and when co-infected with HCV, it is better to imagine the two pathogens than they can actually be managed.

The seroprevalence of HCV and malaria infectivity is high in central Nigeria. This study findings guide the want for routine $\mathrm{HCV}$ and malaria screening among pregnant women at some stage in antenatal care within the region and Nigeria. It will also form a base for continual education campaign about HCV amongst rural/Urban pregnant mothers/women and food vendors in central states and other parts of Nigeria. Those efforts will guarantee top of the line and better outcome for excellent health care delivery for the expecting mothers and other health care providers in our hospitals.

\section{Abbreviations}

HCV: Hepatitis C Virus

RNA: Ribonucleic acid

HIV: Human immunodeficiency virus

HSPGs: Heparan sulfate (HS) polysaccharide chains

CD-81: Cluster of Differentiation 81

SR-B1: Scavenger receptor B1

ApoE: Apolipoprotein E

\section{Declarations}

\section{Ethical Approval and Consent to participate}

The study was conducted following ethical approval from the Institutional Review Board (IRB) of Nasarawa state University. Official permission was obtained from National Hospital Abuja administrators and antenatal care units through an official letter of support from Nasarawa state University Research 
Director. The purpose of the study, the right to refuse or participate in the study, and the anonymity and confidentiality of the information collected were explained to each study participant.

\section{Consent for publication}

Not applicable

\section{Availability of data and materials}

Data is contained in the body of the manuscript. Although, data sets generated and analysed during the current study some are not publicly available due to anonymity policy issues but are available from the corresponding author upon request.

\section{Competing interests}

The authors declare that they have no competing interests

\section{Funding}

This work was not funded by any organization.

\section{Authors contributions}

PA: Design the project, collected the data, and wrote the manuscript

HS: Design the study, collected the data and statistical analysis.

OA: Contributed to statistical analysis and took part in the data collection and participated in all phases of the work, contributed to writing of the manuscript, was the main supervisor.

All authors read and approved the manuscript for submission.

\section{Acknowledgements}

We wish to express our immense gratitude to staff of Federal Medical Centre Keffi, Zankli Medical Centre Abuja, National Hospital Abuja and all the patients and staff of the all participating Hospitals.

\section{References}

1. Boriskin, Yury S, AU Pécheur, Eve-Isabelle AU, Polyak, Stephen J.PY. Arbidol: a broad-spectrum antiviral that inhibits acute and chronic HCV infection. Virology Journal. 2006; 56; 3-1 /doi.org/10.1186/1743-422X-3-56

2. Ryan EL, Morgello S, Isaacs K, Naseer M, Gerits P, Manhattan HIV Brain Bank. Neuropsychiatric impact of hepatitis C on advanced HIV. Neurology. 2004;62(6):957-62. 
3. Alter MJ. Epidemiology of hepatitis C virus infection. World J Gastroenterol. 2007;13(17):2436-41.

4. Dibba P, Cholankeril R, Li AA, et al. Hepatitis C in Pregnancy. Diseases. 2018;6(2):31. Published 2018 Apr 27. doi:10.3390/diseases6020031

5. Guinovart, C.; Navia, M. M.; Tanner, M.; Alonso, P. L. Malaria; Burden of diseases. Current Molecular Medicine. 6; 2. 2006. 137-140(4). DOI: https://doi.org/10.2174/156652406776055131

6. Perkins DJ, Weinberg JB, Kremsner PG. Reduced interleukin-12 and transforming growth factor $\beta 1$ in severe childhood malaria: relationship of cytokine balance with disease severity. Journal of Infectious Diseases. 2000;182:988-992. [PubMed]

7. Ho M, Sexton MM, Tongtawe P, Looareesuwan S, Suntharasamai P, Webster HK. Interleukin-10 inhibits tumour necrosis factor production but not antigen-specific lymphoproliferation in acute Plasmodium falciparum malaria. Journal of Infectious Diseases. 1995;172:838-844. [PubMed].

8. Foulds KE, Wu C, Seder RA. Th1 memory: implications for vaccine development. Immunology Reviews. 2006;211:58-66. [PubMed].

9. Gasim GI, Adam I) Hepatitis B Hepatitis C virus and Malaria co-infection. Int J Vaccine Immunizat 2015;1(1): doi: http://dx.doi. org/10.16966/2470-9948.101

10. Okwa OO The status of malaria among pregnant women: a study in Lagos, Nigeria. Afr J Reprod Health. 2003 Dec; 7(3):77-83.

11. Dennis N. Aribodor, Obioma C. Nwaorgu, Christine. Eneanya, Ikechukwu Okoli, Reed Pukkila-Worley and Harrison O. Etaga. Association of low birth weight and placental malarial infection in Nigeria. $\mathrm{J}$ Infect Dev Ctries 2009; 3(8):620-623.

12. Anna M van Eijk, Jenny Hill, Abdisalan M Noor, Robert W Snow, Feiko $O$ ter Kuile. Prevalence of malaria infection in pregnant women compared with children for tracking malaria transmission in subSaharan Africa: a systematic review and meta-analysis. Lancet Glob Health 2015; 3: e617-28

13. Shereen Mansour Galal , Fardous Hanem Abdel Aal , Alam El-den Mohammed, Mohamed Zidan Mohamed, Yasser Gamal Abd El-Rahman. Chronic viral hepatitis $\mathrm{C}$ in pediatric age group; assessment of viral activity and hepatic fibrosis by $1 \mathrm{H}$ magnetic resonance spectroscopy and diffusion weighted imaging in asymptomatic patient. The Egyptian Journal of Radiology and Nuclear Medicine .2016; 47, $739-748$

14. Atrah $\mathrm{HI}$, Ahmed MM. Hepatitis $\mathrm{C}$ virus seroconversion by a third generation ELISA screening test in blood donors. J Clin Pathol. 1996; 49(3):254-5.

15. Luce Marina Freires Corrêa da Costa, Aparecida Duarte Hg Mussi , Marylina Rodrigues Brianeze and Francisco José Dutra Souto. Hepatitis C as a Risk Factor for Diabetes Type 2: Lack of Evidence in a 
Hospital in Central-West. Brazil. Braz J Infect 200812 http://dx.doi.org/10.1590/S141386702008000100007

16. Carla W. Brady, Andrew J. Muir. The impact of race and ethnicity on the treatment of hepatitis $C$ disease. Current Hepatitis Reports, 2006; 5 (3) 79

17. Oni,A, Odaibo,G.N. , Olaleye,O.D., Bakare,R.A., Ola, S.O. Sero-prevalence of hepatitis $C$ virus amoung patients attending STD clinic in Ibadan, Nigeria. Afr. J. Clin. Exper. Microbiol. 6(1) 2005: 53-5918.

18. Catherine S. Todd, Abdullah M.S. Abed, Steffanie A. Strathdee, Paul T. Scott, Boulos A. Botros, Naqibullah Safi and Kenneth C. Earhart. HIV, Hepatitis C, and Hepatitis B Infections and Associated Risk Behavior in Injection Drug Users, Kabul, Afghanistan. Emerg Infect Dis. 2007; 13(9): 13271331.doi: 10.3201/eid1309.070036

19. Reuben R. Women and malaria--special risks and appropriate control strategy. Soc Sci Med. 1993;37 (4):473-80.

20. Chauhan, RC Negi, B Verma, S Thakur. Transfusion Transmitted Malaria in a Non-Endemic Area. JAPI.2009;57:653-654.

21. Robert Slinger, Antonio Giulivi, Margaret Bodie-Collins, Farid Hindieh, Ron St. John, Graham Sher, Mindy Goldman, Maura Ricketts and Kevin C. Kain. Transfusion-transmitted malaria in Canada. CMAJ, 2001164 (3) 377-379.

22. Bruce-Chwatt LJ. Transfusion malaria revisited. Trop Dis Bull. 1982. 79(10):827-40.

23. Chigozie Jesse Uneke, Ogbonnaya Ogbu, and Vincent Nwojiji. Potential risk of induced malaria by blood transfusion in South-eastern Nigeria. Mcgill J Med. 2006 Jan; 9(1): 8-13.

24. Nwuzo, A.C. Ogbu,O., Iroha, R.I.,Afiukwa, F.N.,Ominyi, M.C., Uhuo, A.C. and Ogbanshi, M.E. The rate of distribution of malaria (Plasmodium falciparum) among HIV positive individuals visiting Saint Theresa's Hospital Abakpa Nike Enugu, Enugu State, Nigeria. European Journal of Experimental Biology, 2013, 3(5):516-520

25. Lowe M, Chen D-R, Huang S-L (2016) Social and Cultural Factors Affecting Maternal Health in Rural Gambia: An Exploratory Qualitative Study. PLoS ONE 11(9): e0163653.

https://doi.org/10.1371/journal.pone.0163653

26. Nita Bhalla INSIGHT-"Put up and shut up": polygamy breeds poverty for Kenyan women and children. Reuters. 2018. https://af.reuters.com/article/commoditiesNews/idAFL4N1UZ2ZI

27. Dibba P, Cholankeril R, Li AA, et al. Hepatitis C in Pregnancy. Diseases. 2018;6(2):31. Published 2018 Apr 27. doi:10.3390/diseases60200 


\section{Tables}

Table 1: Seropevalance (\%) of Hepatitis C virus infection in relation to age, previous blood transfusion, surgery and HIV status of patients.

\begin{tabular}{|c|c|c|c|c|}
\hline $\begin{array}{l}\text { Demographic } \\
\text { Character }\end{array}$ & No. Examined & No. Positive & $\chi^{2}$ : value & $P$ value \\
\hline Age & & & .2017 & .9930 \\
\hline $15-25$ & $47(36.2 \%)$ & $9(19.2 \%)$ & & \\
\hline $26-36$ & $58(44.8 \%)$ & $10(17.2 \%)$ & & \\
\hline$>37$ & $25(19.2 \%)$ & $3(12 \%)$ & & \\
\hline Blood transfusion & & & .7719 & .3796 \\
\hline Yes & $26(20.0 \%)$ & $2(7.7 \%)$ & & \\
\hline No & $104(80.0 \%)$ & $20(19.2 \%)$ & & \\
\hline Previous Surgery & & & .4190 & .5174 \\
\hline Yes & 31 (23.9\%) & $8(25.8 \%)$ & & \\
\hline No & $99(76.2 \%)$ & $14(14.1 \%)$ & & \\
\hline HIV Status & & & .0909 & .2962 \\
\hline Positive & $23(17.7 \%)$ & 7(30.4\%) & & \\
\hline Negative & 107(82.3\%) & $15(14.0 \%)$ & & \\
\hline
\end{tabular}

P-value $<0.05=$ statistically significant

P-value $>0.05=$ not statistically significant

\section{Keys:}

No. $=$ Number, $\mathrm{Yr}=$ Years, $\%=$ Percentage, $>=$ Greater than, $\chi^{2}=$ Chi-square,

$\mathrm{P}$ value $=$ Probability value

Table 2: Seroprevalence (\%) of Hepatitis C virus infection in relation to marital status, Family type, Body piercing and Educational status of patients. 


\begin{tabular}{|c|c|c|c|c|}
\hline Demographic Characteristics & No. Examined & No. Positive & $\chi^{2}$ : value & $P$ value \\
\hline Marital Status & & & .4742 & .7889 \\
\hline Single & $16(12.3 \%)$ & $1(6.3 \%)$ & & \\
\hline Married & 106(81.5\%) & $21(19.8 \%)$ & & \\
\hline Divorced & $8(6.2 \%)$ & $0(0.0 \%)$ & & \\
\hline Family Type & & & .8199 & .3651 \\
\hline Monogamous & 76(58.5\%) & $9(11.8 \%)$ & & \\
\hline Polygamous & $54(41.5 \%)$ & $13(24.1 \%)$ & & \\
\hline Body Piercing & & & .3768 & .8283 \\
\hline Tattoo & $5(3.9 \%)$ & $2(40.0 \%)$ & & \\
\hline Tribal Mark & $53(40.8 \%)$ & $9(17.0 \%)$ & & \\
\hline No Mark & $72(55.4 \%)$ & $11(15.3 \%)$ & & \\
\hline Educational Status & & & .3810 & .9840 \\
\hline Qur'anic & $5(3.1 \%)$ & $1(20.0 \%)$ & & \\
\hline Primary & $11(8.5 \%)$ & $1(9.1 \%)$ & & \\
\hline Secondary & $44(33.9 \%)$ & $7(15.9 \%)$ & & \\
\hline Tertiary & $59(45.4 \%)$ & $11(18.6 \%)$ & & \\
\hline No Formal Education & $11(8.5 \%)$ & $2(18.2 \%)$ & & \\
\hline
\end{tabular}

P-value $<0.05=$ statistically significant

P-value $>0.05=$ not statistically significant

Keys: No. $=$ Number, $\mathrm{Yr}=$ Years, $\%=$ Percentage, $>=$ Greater than, $\chi^{2}=$ Chi-square, P. value.

Table 3: Seropevalance (\%) of Malaria infection in relation to age, previous blood transfusion, surgery and HIV status. 


\begin{tabular}{|c|c|c|c|c|}
\hline $\begin{array}{l}\text { Demographic } \\
\text { Character }\end{array}$ & No. Examined & No. Positive & $\chi^{2}$ : value & $P$ value \\
\hline Age & & & .1093 & .9468 \\
\hline $15-25$ & $47(36.2 \%)$ & $27(57.5 \%)$ & & \\
\hline $26-36$ & $58(44.6 \%)$ & $38(65.5 \%)$ & & \\
\hline$>37$ & $25(19.2 \%)$ & $13(52.0 \%)$ & & \\
\hline Blood transfusion & & & .0001 & 1.0000 \\
\hline Yes & $26(20.0 \%)$ & $16(61.5 \%)$ & & \\
\hline No & $104(80.0 \%)$ & $62(59.6 \%)$ & & \\
\hline Previous Surgery & & & .1527 & .2829 \\
\hline Yes & 31 (23.9\%) & $29(93.6 \%)$ & & \\
\hline No & $99(76.2 \%)$ & $49(49.5 \%)$ & & \\
\hline HIV Status & & & .1050 & .0001 \\
\hline Positive & 107(82.3\%) & $12(11.2 \%)$ & & \\
\hline Negative & $23(17.7 \%)$ & $66(28.0 \%)$ & & \\
\hline
\end{tabular}

P-value $<0.05=$ statistically significant

P-value $>0.05=$ not statistically significant

\section{Keys:}

No. $=$ Number, $\mathrm{Yr}=$ Years, $\%=$ Percentage,$>=$ Greater than, $\chi^{2}=$ Chi-square,

$\mathrm{P}$ value $=$ Probability value

Table 4 Seroprevalence (\%) of Malaria infection in relation to marital status, Family type, Body piercing and Educational status of patients. 


\begin{tabular}{|c|c|c|c|c|}
\hline Demographic Characteristics & No. Examined & No. Positive & $\chi^{2}$ : value & $\mathrm{P}$ value \\
\hline Marital Status & & & .1047 & .9490 \\
\hline Single & $16(12.3 \%)$ & $10(62.5 \%)$ & & \\
\hline Married & $106(81.5 \%)$ & $63(29.4 \%)$ & & \\
\hline Divorced & $8(6.2 \%)$ & $5(62.5 \%)$ & & \\
\hline Family Tyре & & & .0001 & 1.0000 \\
\hline Monogamous & $76(58.5 \%)$ & $45(59.2 \%)$ & & \\
\hline Polygamous & $54(41.5 \%)$ & $33(61.1 \%)$ & & \\
\hline Body Piercing & & & .0276 & .9863 \\
\hline Tattoo & $5(3.9 \%)$ & $3(60.0 \%)$ & & \\
\hline Tribal Mark & $53(40.8 \%)$ & $30(56.6 \%)$ & & \\
\hline No Mark & $72(55.4 \%)$ & $45(62.5 \%)$ & & \\
\hline Educational Status & & & .9912 & .9912 \\
\hline Qur'anic & $5(3.1 \%)$ & $3(60.0 \%)$ & & \\
\hline Primary & $11(8.5 \%)$ & $8(72.7 \%)$ & & \\
\hline Secondary & $44(33.9 \%)$ & $30(56.6 \%)$ & & \\
\hline Tertiary & $59(45.4 \%)$ & $30(50.9 \%)$ & & \\
\hline No Formal Education & $11(8.5 \%)$ & $7(63.6 \%)$ & & \\
\hline
\end{tabular}

P-value $<0.05=$ statistically significant

P-value $>0.05=$ not statistically significant

Keys: No. $=$ Number, $\mathrm{Yr}=$ Years, $\%=$ Percentage, $>=$ Greater than, $\chi^{2}=$ Chi-square, $\mathrm{P}$. value.

Table 5 Seropevalance (\%) of Hepatitis C virus and Malaria co-infection in relation to age, previous blood transfusion, surgery and HIV status of patients examined. 


\begin{tabular}{|c|c|c|c|c|}
\hline $\begin{array}{l}\text { Demographic } \\
\text { Character }\end{array}$ & No. Examined & No. Positive & $\chi^{2}$ : value & $P$ value \\
\hline Age & & & 2.8795 & .2369 \\
\hline $15-25$ & $47(36.2 \%)$ & $7(14.9 \%)$ & & \\
\hline $26-36$ & $58(44.8 \%)$ & $6(10.4 \%)$ & & \\
\hline$>37$ & $25(19.2 \%)$ & $1(4.0 \%)$ & & \\
\hline Blood transfusion & & & .2435 & .6217 \\
\hline Yes & $26(20.0 \%)$ & $2(7.7 \%)$ & & \\
\hline No & $104(80.0 \%)$ & $12(11.5 \%)$ & & \\
\hline Previous Surgery & & & 1.3476 & .2456 \\
\hline Yes & 31 (23.9\%) & $7(22.6 \%)$ & & \\
\hline No & $99(76.2 \%)$ & $7(7.1 \%)$ & & \\
\hline HIV Status & & & .0065 & .9360 \\
\hline Positive & 23(17.7\%) & $2(8.7 \%)$ & & \\
\hline Negative & 107(82.3\%) & $12(11.2 \%)$ & & \\
\hline
\end{tabular}

P-value $<0.05=$ statistically significant

P-value $>0.05=$ not statistically significant

\section{Keys:}

No. $=$ Number, $\mathrm{Yr}=$ Years, $\%=$ Percentage,$>=$ Greater than, $\chi^{2}=$ Chi-square,

$\mathrm{P}$ value $=$ Probability value

\section{Supplementary Files}

This is a list of supplementary files associated with this preprint. Click to download.

- QESTIONNAIRES2019.docx 